\title{
Detection of non-milk fat in milk fat by gas chromatography and linear discriminant analysis
}

\author{
R. Gutiérrez,, ${ }^{* 1}$ S. Vega,, G. Díaz, ${ }^{*}$ J. Sánchez,† M. Coronado, ${ }^{*}$ A. Ramírez, ${ }^{*}$ J. Pérez, ${ }^{*}$ M. González, \\ and B. Schettino* \\ *Departamento de Producción Agrícola y Animal, and \\ †Departamento del Hombre y su Ambiente, Universidad Autónoma Metropolitana Unidad Xochimilco, Calz. Hueso 1100, Villa Quietud, \\ 04960 Coyoacán, México D.F. México
}

\section{ABSTRACT}

Gas chromatography was utilized to determine triacylglycerol profiles in milk and non-milk fat. The values of triacylglycerol were subjected to linear discriminant analysis to detect and quantify non-milk fat in milk fat. Two groups of milk fat were analyzed: A) raw milk fat from the central region of Mexico $(\mathrm{n}=216)$ and $\mathrm{B})$ ultrapasteurized milk fat from 3 industries $(\mathrm{n}=36)$, as well as pork lard $(\mathrm{n}=2)$, bovine tallow $(\mathrm{n}=2)$, fish oil $(\mathrm{n}=2)$, peanut $(\mathrm{n}=2)$, corn $(\mathrm{n}=2)$, olive $(\mathrm{n}=$ $2)$, and soy $(n=2)$. The samples of raw milk fat were adulterated with non-milk fats in proportions of 0,5 , 10, 15, and $20 \%$ to form 5 groups. The first function obtained from the linear discriminant analysis allowed the correct classification of $94.4 \%$ of the samples with levels $<10 \%$ of adulteration. The triacylglycerol values of the ultrapasteurized milk fats were evaluated with the discriminant function, demonstrating that one industry added non-milk fat to its product in $80 \%$ of the samples analyzed.

Key words: gas chromatography, linear discriminant analysis, non-milk fat, milk fat

\section{INTRODUCTION}

According to the International Dairy Federation (IDF/FIL, 1995), milk is defined as "the product of the normal secretion of the udder, obtained by one or several milkings, with no addition or subtraction." Mexican legislation (NOM-155-SCFI-2003) establishes, among other specifications, that whole milk for human consumption must contain only its own fat; therefore, addition of non-milk fat (NMF) to milk and derivatives is considered fraud if it is not specified on the label.

Studies related to the detection and quantification of foreign fats in milk and dairy products have been devel-

Received August 13, 2008.

Accepted November 23, 2008.

${ }^{1}$ Corresponding author: reygut@correo.xoc.uam.mx oping for more than $30 \mathrm{yr}$, constituting priority areas in many research centers, with high economic significance in national and international commerce (Parodi, 1971; Pinto et al., 2002; Fontecha et al., 2006). For instance, criteria have been established for the detection of adulteration by fatty acid (FA) quotients (Parodi, 1971; Timms, 1980); in 112 Australian butter samples it was found that $59.8 \%$ of the samples were not detected at an adulteration level of $10 \%$ and $35.7 \%$ were not found at an adulteration level of $15 \%$ (Parodi, 1971). It has also been observed that triacylglycerol (TAG) quotient analysis offers a greater percentage of correct classification (Parodi, 1973; Juárez, 1983).

Timms (1980) suggested another option to detect and quantify adulterations in milk fat (MF) using multiple linear regression with TAG with carbon numbers 40, 42 , and 44 as variables. The proposal was evaluated in 76 samples of Australian butters that were adulterated in different percentages with NMF of animal origin; the equation could detect quantities as low as $5 \%$ of adulteration with $99 \%$ reliability.

The multiple linear regression analysis was used in Germany (Precht, 1992a, b), and 6 specific equations for pure MF were obtained to detect foreign fats at levels of 2,4 , and $8 \%$ of incorporation with $95 \%$ reliability; when the adulteration level was $15 \%$, detection had $99 \%$ reliability. Consequently, the European Union made the methodology official, converting it to a reference method for the detection of foreign fat in milk fat by TAG analysis by GC (European Community, 2001).

Discriminant analysis is another option to detect foreign fat in milk. In Chile, a discriminant function allowed a classification of 97.2 or $79.1 \%$ of adulterated samples containing 10 or 5\%, respectively, of animalorigin fat (Pinto et al., 2002).

In Mexico some studies have been published about the establishment of the FA profile in milk fat: raw, powder, and pasteurized (Pérez et al., 1998). Likewise, the TAG profile has also been obtained in UHT MF from 4 industries with wide distribution in national 
markets (Vega et al., 1999); therefore, in Mexico, there is evidence of studies on FA and TAG composition in milk fat, but few on raw milk fat. Also, in the literature review, we found only one publication on the combined use of GC, TAG, and linear statistical models in the detection of foreign fat in milk and its derivatives (Gutiérrez et al., 2007). Therefore, the objective of this study was to develop and validate a method based on TAG analysis by GC combined with the statistical technique of the linear discriminant analysis (LDA) to detect NMF in MF, at incorporation levels $<5 \%$.

\section{MATERIAL AND METHODS}

\section{Sample Collection}

Raw MF. A collection was made of 216 samples of $1 \mathrm{~L}$ every $15 \mathrm{~d}$ over 12 mo from 2 production units of the Federal District $(\mathrm{n}=49$; an additional sample was obtained), 4 from the state of Mexico ( $\mathrm{n}=107$; 11 additional samples were obtained), and 3 from the state of Hidalgo $(n=60$; at times the sampling was not completed in the 3 production units). The collection of samples was carried out according to the methodology proposed by the IDF/FIL (1995) and by Norma Mexicana NMX-F-718-COFOCALEC-2006. The fatty material was extracted by means of detergent (Frank et al., 1975) and was kept at $-20^{\circ} \mathrm{C}$ until its analysis.

UHT $\boldsymbol{M F}$. One-liter samples $(\mathrm{n}=36)$ of UHT milk were obtained monthly for 12 mo from 3 industries that sell their products in the supermarkets of Mexico City. The fat matter was extracted and stored under similar conditions as used for raw milk.

NMF Samples. Two samples each (250 mL each) of fish, peanut, corn, olive, and soy oils were obtained from oil industries located in Mexico City. In addition, 2 samples of pork lard and 2 of bovine tallow (100 g each) were obtained from markets of Mexico City. The fat matter was extracted and purified in a way similar to that proposed for butter by the International Dairy Federation (FIL/IDF, 1995) and in accordance to the Official Mexican Norm (NOM-021-ZOO-1995).

\section{Chromatographic Analysis}

A Perkin-Elmer Autosystem 9000 gas chromatograph (Perkin Elmer, Norwalk, CT) was used, with flameionization detector and PE Nelson 1022 area integrator. The injector temperature (split-splitless) was set at $340^{\circ} \mathrm{C}$, detector temperature (flame-ionization detector) at $350^{\circ} \mathrm{C}$, and carrier gas flow (helium) at $1 \mathrm{~mL} /$ min. The oven temperature was programmed as follows: temperature $1=200^{\circ} \mathrm{C}$ min with $5^{\circ} \mathrm{C}$ increments up to $325^{\circ} \mathrm{C}$; temperature $2=325^{\circ} \mathrm{C}$ for $6 \mathrm{~min}$; total run time of $31 \mathrm{~min}$; and injection volume of $1 \mu \mathrm{L}$. The column was phenyl methyl silicon at $5 \%$, intermediate polarity HP5, $2 \mathrm{~m} \times 0.25 \mathrm{~mm}$ internal diameter $\times$ 0.25- $\mu \mathrm{m}$ layer thickness (Hewlett Packard, Palo Alto, CA). To identify and quantify TAG, a comparison of chromatograms obtained from the different fat samples (retention times and peak areas) was made with the chromatogram of the standard mixture.

\section{Standard Preparation and Correction Factor Determination}

The TAG standard utilized (100 mg at 99\% ampule, Sigma 178-11) contained tricaprylin (C8:0) 20\%; tricaprin (C10:0) 20\%; trilaurin (C12:0) 20\%; trymiristin (C14:0) 20\%; and tripalmitin (C16:0) 20\%.

The 100-mg ampule was dissolved in $5 \mathrm{~mL}$ of $n$ hexane. One microliter of the solution was injected 5 times to determine the retention time and the area percentage for each TAG. The average, minimum, and maximum retention times were calculated. The average area percentage was calculated and the correction factors were calculated considering the response factor for trilaurin (C36) as 1.0 and using the formula $\mathrm{f}_{\mathrm{x}}=\mathrm{CX} / \mathrm{C} 36 \times \mathrm{A}_{\mathrm{C} 36} / \mathrm{A}_{\mathrm{CX}}$, where $\mathrm{f}_{\mathrm{x}}=$ triacylglycerol $x$ correction factor; $\mathrm{CX}=$ standard triacylglycerol $x$ $(\mathrm{mg} / \mathrm{mL})$ concentration; C36 = trilaurin concentration $(\mathrm{mg} / \mathrm{mL}) ; \mathrm{A}_{\mathrm{C} 36}=$ trilaurin area; and $\mathrm{A}_{\mathrm{CX}}=$ standard triacylglycerol $x$ area. The correction factors should not be greater than 1.01 .

\section{Data Description and Variables}

Three data groups were formed: 1) MF, 2) UHT MF, and 3) NMF (vegetable and animal). For each of the groups, independent variables $(\mathrm{x})$ were defined as "TAG percentage with carbon $\mathrm{j}$ pair number."

For the definition of the utilized groups in the LDA, different adulteration levels were considered as follows: group $1=$ pure MF samples ( $0 \%$ adulteration); group $2=$ adulterated samples at $5 \%$ adulteration; group 3 $=$ adulterated samples at 10\% adulteration; group $4=$ adulterated samples at $15 \%$ adulteration; group $5=$ adulterated samples at $20 \%$ adulteration.

\section{Preparation of Adulterated Samples}

The procedure for the adulteration of MF with different levels of NMF was based on the following simulation formula (Timms, 1980):

$$
\mathrm{Ci}^{\mathrm{MIX}}=\mathrm{xCi}^{\mathrm{NMF}}+(1-\mathrm{x}) \mathrm{Ci}^{\mathrm{PMF}},
$$

where $\mathrm{x}=\mathrm{NMF}$ fraction; $\mathrm{Ci}=$ TAG percentage with carbon i number; MIX, NMF, PMF = mixture, NMF, 
Table 1. Triacylglycerol (\% wt/wt) levels in raw milk fat from 3 regions of Mexico

\begin{tabular}{|c|c|c|c|c|c|c|c|}
\hline Triacylglycerol & \multicolumn{2}{|c|}{ Mexico City $(\mathrm{n}=49)$} & \multicolumn{2}{|c|}{ State of Mexico $(n=107)$} & \multicolumn{2}{|c|}{ Hidalgo $(\mathrm{n}=60)$} & Global mean \\
\hline $\mathrm{C} 28$ & $0.53^{\mathrm{a}}$ & 0.18 & $0.39^{\mathrm{b}}$ & 0.19 & $0.44^{\mathrm{b}}$ & 0.21 & 0.45 \\
\hline C32 & $1.48^{\mathrm{a}}$ & 0.69 & $1.33^{\mathrm{a}}$ & 0.48 & $1.53^{\mathrm{a}}$ & 0.40 & 1.45 \\
\hline C34 & $3.43^{\mathrm{a}}$ & 1.09 & $3.401^{\mathrm{a}}$ & 1.03 & $3.40^{\mathrm{a}}$ & 0.80 & 3.41 \\
\hline C36 & $7.12^{\mathrm{a}}$ & 1.65 & $7.15^{\mathrm{a}}$ & 1.66 & $7.07^{\mathrm{a}}$ & 1.41 & 7.11 \\
\hline $\mathrm{C} 44$ & $5.62^{\mathrm{a}}$ & 1.63 & $4.70^{\mathrm{b}}$ & 1.53 & $5.50^{\mathrm{a}}$ & 1.85 & 5.27 \\
\hline $\mathrm{C} 46$ & $7.03^{\mathrm{a}}$ & 1.62 & $6.16^{\mathrm{b}}$ & 1.24 & $6.57^{\mathrm{ab}}$ & 1.27 & 6.59 \\
\hline $\mathrm{C} 48$ & $9.67^{\mathrm{a}}$ & 2.01 & $9.42^{\mathrm{a}}$ & 1.23 & $8.94^{\mathrm{a}}$ & 1.34 & 9.34 \\
\hline $\mathrm{C} 50$ & $12.91^{\mathrm{a}}$ & 3.38 & $14.53^{\mathrm{b}}$ & 2.80 & $12.86^{\mathrm{a}}$ & 3.62 & 13.43 \\
\hline C52 & $13.02^{\mathrm{a}}$ & 4.42 & $16.68^{\mathrm{b}}$ & 5.24 & $14.23^{\mathrm{a}}$ & 5.29 & 14.64 \\
\hline C54 & $7.91^{\mathrm{a}}$ & 3.69 & $9.75^{\mathrm{a}}$ & 3.93 & $8.18^{\mathrm{a}}$ & 2.94 & 8.61 \\
\hline
\end{tabular}

${ }^{\mathrm{a}, \mathrm{b}}$ Means within a row with different superscripts differ $(P<0.05)$.

and pure MF, respectively. Adulterated samples were used to constitute different groups subjected to discriminant analysis.

\section{Statistical Techniques}

We applied a univariate statistical summary for variables used (TAG from C28 to C54, \% wt/wt). Some of the reasons why this technique was used were data inspection, atypical value identification, description, assumed verification, and characterization of differences between sub-populations (case groups). One-way variance analysis followed by Tukey test for means comparison. We considered variance as milk origin (brands and MF and NMF mixtures). We used simple linear regression, analysis of principal components for the selection of the variables with the purpose to pos- tulate an appropriate measure of total variance of the explanatory variables (TAG), and LDA (SPSS, 1997; Afifi et al., 2004).

\section{RESULTS AND DISCUSSION}

\section{TAG in MF}

The chromatographic conditions allowed the identification and quantification of TAG of 28 to 54 carbons in raw milk and UHT MF. The composition of TAG (\% $\mathrm{wt} / \mathrm{wt}$ ) of fat from milks produced in the 3 regions of study is described in Table 1 . The statistical analysis indicated a significant difference $(P<0.05)$ for TAG C28, C40, C42, C44, C46, C50, and C52 in the state of Mexico. In Hidalgo, a significant difference $(P<0.05)$ in C28, C40, C42, and C44 compared with samples

Table 2. Triacylglycerol (\% wt/wt) levels in UHT milk fat from 3 Mexican dairy industries

\begin{tabular}{|c|c|c|c|c|c|c|}
\hline \multirow[b]{2}{*}{ Triacylglycerol } & \multicolumn{2}{|c|}{ UHT1 (n = 12) } & \multicolumn{2}{|c|}{ UHT2 (n = 12) } & \multicolumn{2}{|c|}{ UHT3 (n = 12) } \\
\hline & Mean & $\mathrm{SD}$ & Mean & $\mathrm{SD}$ & Mean & $\mathrm{SD}$ \\
\hline $\mathrm{C} 28$ & $0.52^{\mathrm{a}}$ & 0.11 & $0.82^{\mathrm{b}}$ & 0.19 & $0.61^{\mathrm{a}}$ & 0.10 \\
\hline C30 & $0.66^{\mathrm{a}}$ & 0.25 & $0.49^{\mathrm{a}}$ & 0.35 & $0.60^{\mathrm{a}}$ & 0.08 \\
\hline C32 & $1.63^{\mathrm{a}}$ & 0.36 & $1.74^{\mathrm{a}}$ & 0.59 & $1.62^{\mathrm{a}}$ & 0.25 \\
\hline C34 & $2.84^{\mathrm{a}}$ & 0.83 & $2.45^{\mathrm{a}}$ & 2.07 & $2.82^{\mathrm{a}}$ & 0.40 \\
\hline C36 & $6.20^{\mathrm{a}}$ & 1.70 & $4.85^{\mathrm{b}}$ & 3.21 & $6.27^{\mathrm{a}}$ & 0.77 \\
\hline C38 & $12.26^{\mathrm{a}}$ & 1.68 & $9.99^{\mathrm{b}}$ & 3.24 & $12.73^{\mathrm{a}}$ & 1.45 \\
\hline $\mathrm{C} 40$ & $15.21^{\mathrm{a}}$ & 1.47 & $9.39^{\mathrm{b}}$ & 3.35 & $15.59^{\mathrm{a}}$ & 1.46 \\
\hline $\mathrm{C} 42$ & $12.15^{\mathrm{a}}$ & 1.64 & $5.73^{\mathrm{b}}$ & 2.95 & $12.24^{\mathrm{a}}$ & 0.84 \\
\hline $\mathrm{C} 44$ & $7.46^{\mathrm{a}}$ & 0.46 & $3.97^{\mathrm{b}}$ & 1.95 & $7.38^{\mathrm{a}}$ & 0.30 \\
\hline $\mathrm{C} 46$ & $7.59^{\mathrm{a}}$ & 0.54 & $4.11^{\mathrm{b}}$ & 1.68 & $7.48^{\mathrm{a}}$ & 0.58 \\
\hline $\mathrm{C} 48$ & $8.72^{\mathrm{a}}$ & 0.64 & $6.64^{\mathrm{b}}$ & 2.16 & $8.15^{\mathrm{a}}$ & 0.97 \\
\hline $\mathrm{C} 50$ & $9.86^{\mathrm{a}}$ & 0.94 & $13.27^{\mathrm{b}}$ & 4.11 & $9.28^{\mathrm{a}}$ & 1.63 \\
\hline C52 & $9.25^{\mathrm{a}}$ & 1.66 & $21.48^{\mathrm{b}}$ & 8.60 & $9.26^{\mathrm{a}}$ & 1.72 \\
\hline C54 & $5.63^{\mathrm{a}}$ & 1.65 & $15.06^{\mathrm{b}}$ & 7.09 & $5.94^{\mathrm{a}}$ & 1.23 \\
\hline
\end{tabular}

${ }^{a, b}$ Means within a row with different superscripts differ $(P<0.05)$. 

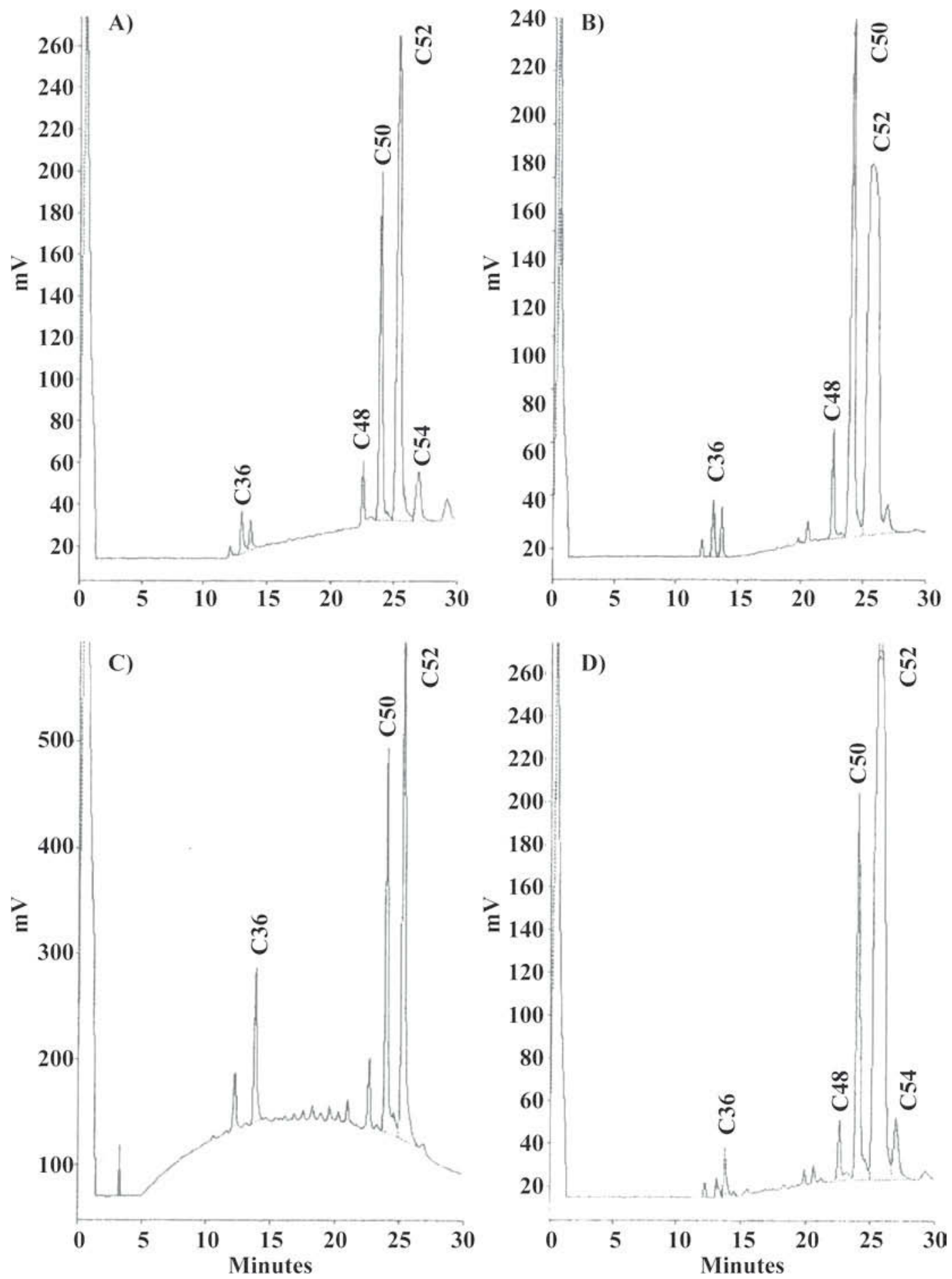

Figure 1. Triacylglycerol chromatograms in vegetable oils (application volume to gas chromatograph $=1 \mu \mathrm{L}$ ): A) peanut oil, B) corn oil, C) olive oil, and D) soy oil.

from Mexico City and in C50 and C52 compared with samples from the state of Mexico. Thus, the states of Mexico and Hidalgo have a similar behavior in TAG C42, C44, and C46, which is probably the result of the components in the diet in each region and, in this sense, the region effect is manifested. The dispersion of the data in respect to the means was estimated with a standard deviation up to 10 times that found by other researchers for Australian and Chilean milk fats (Parodi, 1973; Pinto et al., 1987; Fontecha et al., 2006). 
GUTIÉRREZ ET AL.
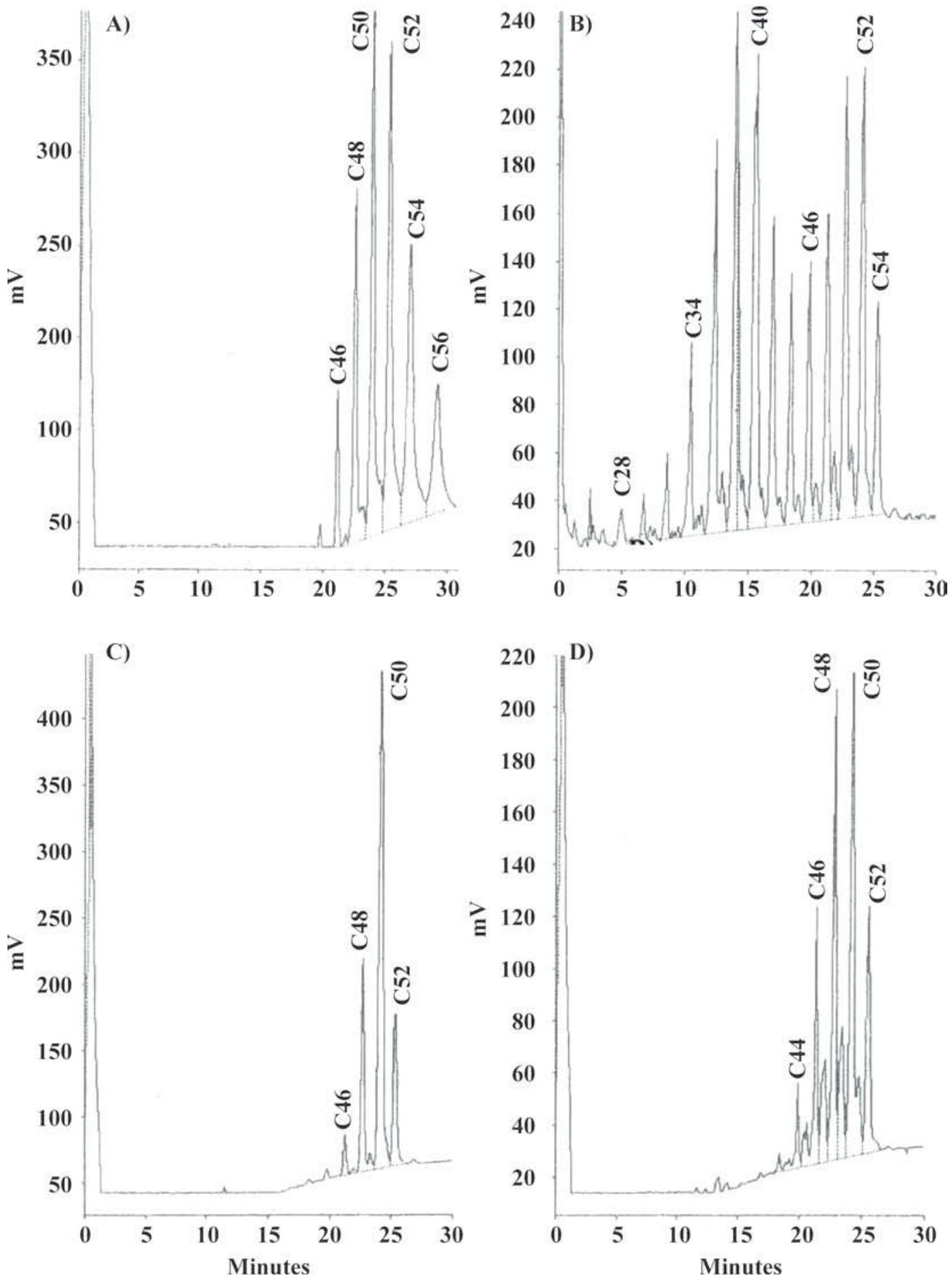

Figure 2. Triacylglycerol chromatograms in animal fats (application volume to gas chromatograph $=1 \mu \mathrm{L}$ ): A) fish oil, B) raw milk, C) pork lard, and D) bovine tallow. 
Table 3. Triacylglycerol (\% wt/wt) levels in non-milk fats

\begin{tabular}{|c|c|c|c|c|c|c|c|c|c|}
\hline Sample & \multicolumn{8}{|c|}{ Triacylglycerol } & Sum \\
\hline Fish oil $(\mathrm{n}=2)$ & $\mathrm{ND}^{1}$ & $\mathrm{ND}$ & 2.63 & 11.38 & 20.98 & 25.59 & 24.02 & 15.39 & 100.00 \\
\hline Corn oil $(\mathrm{n}=2)$ & 1.72 & ND & $\mathrm{ND}$ & 3.23 & 28.84 & 66.21 & ND & ND & 100.00 \\
\hline Olive oil $(\mathrm{n}=2)$ & 6.27 & ND & ND & 3.23 & 28.84 & 66.21 & ND & ND & 100.00 \\
\hline Soy oil $(\mathrm{n}=2)$ & 0.67 & ND & ND & 2.01 & 17.09 & 74.54 & 5.69 & ND & 100.00 \\
\hline
\end{tabular}

${ }^{1} \mathrm{ND}=$ nondetectable $(<0.01, \% \mathrm{wt} / \mathrm{wt})$.

In Table 2, TAG levels (\% wt/wt) obtained in UHT $\mathrm{MF}$ are reported. It was observed that TAG levels present in fats of industries 1 and 3 were similar $(P \geq$ $0.05)$. Industry 2 showed similarities $(P \geq 0.05)$ with industries 1 and 3 in TAG C30, C32, C34, and C36.

\section{TAG in NMF}

Triacylglycerol profiles present in NMF are shown in Figures 1 and 2. The chromatographic conditions allowed us to obtain defined peaks for TAG of C36 medium molecular weight found in fats of vegetable origin, as well as TAG of high molecular weight (C46 to C56) found in animal and vegetable fats. Six chromatographic signals were identified in fish and peanut oils; 5 in pork lard, bovine tallow, and soy oil; 4 in sunflower and corn oil, and 3 in olive oil. The identified TAG were between C36 and C56, being qualitatively and quanti- tatively different in each of the fats in question. Fish oil, pork lard, and bovine tallow were characterized by having C46 and C48, whereas they lacked C36, which was found in all vegetable oils. In vegetable oils except peanut oil, C48, C50, and C52 were found. These TAG profiles in animal and vegetable fats coincide with reports in similar studies performed in Germany (Precht, 1992a, b). Milk fat showed greater complexity than NMF (Figures 1 and 2).

The levels of TAG (\% wt/wt) in oils, pork lard, and bovine tallow are shown in Table 3. Fish oil showed values greater than $20 \%$ for each of the TAG C50, C52, and C54, and these 3 TAG comprised $70.59 \%$ of all TAG; this oil contains FA with carbon numbers from 14 to 22 and with different degrees of unsaturation, just as MF offers a variety of molecular species (Destaillats et al., 2006; Molketin, 2007). Peanut, corn, olive, and soy oils, which contain considerable proportions of lino-

Al1-groups Stacked Histogram

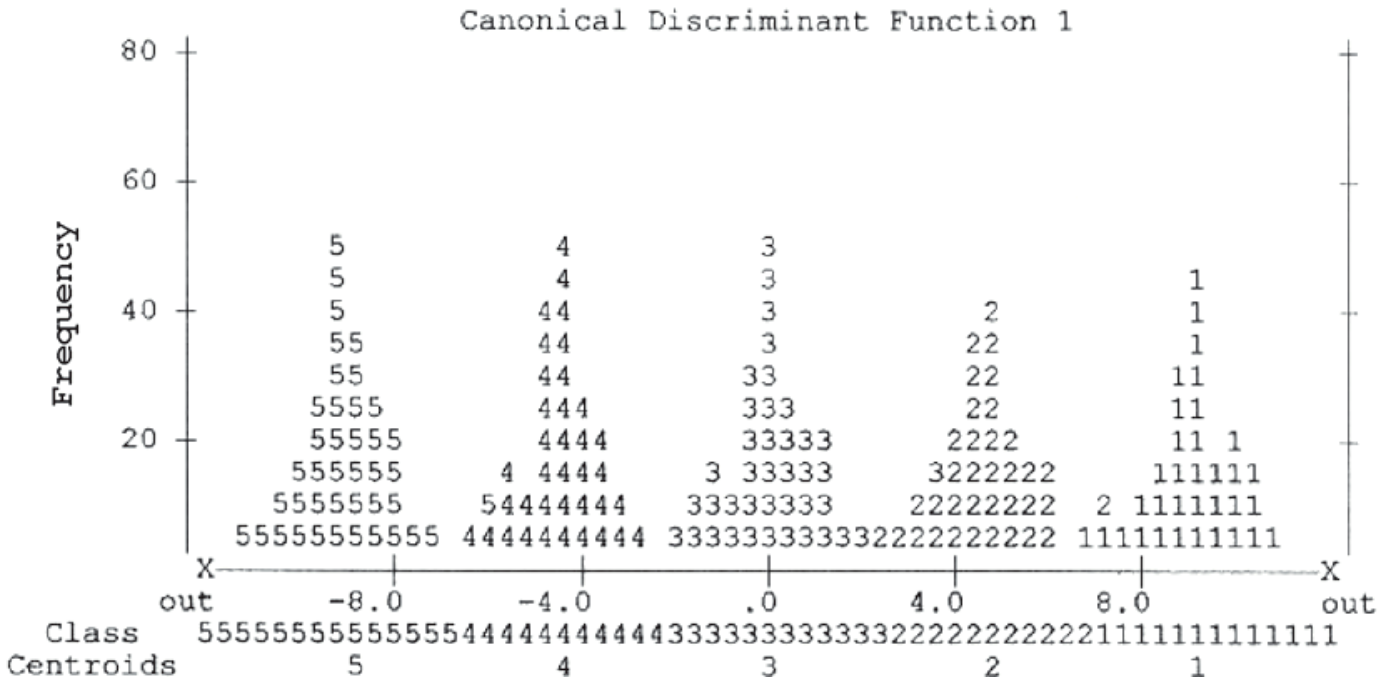

Figure 3. Groups classified by discriminant function: $1=$ samples of authentic milk fat, $0 \%$ adulteration; $2=$ samples of adulterated milk fat at $5 \% ; 3=$ samples of adulterated milk fat at $10 \% ; 4=$ samples of adulterated milk fat at $15 \%$; and $5=$ samples of adulterated milk fat at $20 \%$. 
Table 4. Triacylglycerol (\% wt/wt) levels in milk fat (MF) and non-milk fat (NMF) mixtures

\begin{tabular}{|c|c|c|c|c|c|c|c|c|c|c|c|c|c|c|c|}
\hline \multirow[b]{2}{*}{ Group (MF + NMF) } & \multicolumn{14}{|c|}{ Triacylglycerol } & \multirow[b]{2}{*}{ Sum } \\
\hline & $\mathrm{C} 28$ & C30 & $\mathrm{C} 32$ & C34 & $\mathrm{C} 36$ & C38 & $\mathrm{C} 40$ & $\mathrm{C} 42$ & $\mathrm{C} 44$ & $\mathrm{C} 46$ & $\mathrm{C} 48$ & $\mathrm{C} 50$ & $\mathrm{C} 52$ & C54 & \\
\hline $100 \% \mathrm{MF}+0 \%$ fish oil & 0.34 & 0.57 & 1.32 & 3.98 & 9.18 & 12.62 & 10.08 & 5.57 & 5.70 & 6.94 & 10.48 & 13.99 & 13.30 & 5.94 & 100.00 \\
\hline $95 \% \mathrm{MF}+5 \%$ fish oil & 0.18 & 0.58 & 1.48 & 2.60 & 7.70 & 12.86 & 10.55 & 5.88 & 5.32 & 7.87 & 10.86 & 14.43 & 13.66 & 6.03 & 100.00 \\
\hline $90 \% \mathrm{MF}+10 \%$ fish oil & 0.52 & 1.13 & 2.12 & 4.99 & 15.38 & 19.17 & 13.38 & 5.81 & 4.54 & 5.12 & 6.71 & 7.55 & 7.51 & 6.09 & 100.00 \\
\hline $85 \% \mathrm{MF}+15 \%$ fish oil & 0.20 & 0.74 & 1.55 & 4.76 & 11.69 & 14.99 & 11.21 & 5.16 & 4.63 & 5.70 & 8.58 & 11.27 & 11.04 & 8.47 & 100.00 \\
\hline $100 \% \mathrm{MF}+0 \%$ peanut oil & 0.23 & 0.77 & 1.01 & 2.49 & 8.14 & 13.55 & 11.56 & 4.88 & 3.92 & 4.49 & 9.84 & 13.44 & 15.87 & 9.81 & 100.00 \\
\hline $95 \% \mathrm{MF}+5 \%$ peanut oil & 0.23 & 0.63 & 1.06 & 2.48 & 7.34 & 12.36 & 10.88 & 4.82 & 4.48 & 4.30 & 9.80 & 13.35 & 16.73 & 11.55 & 100.00 \\
\hline $90 \% \mathrm{MF}+10 \%$ peanut oil & 0.18 & 0.60 & 1.08 & 2.60 & 6.68 & 11.48 & 10.23 & 4.46 & 3.37 & 3.89 & 8.87 & 12.80 & 17.57 & 16.21 & 100.00 \\
\hline $85 \% \mathrm{MF}+15 \%$ peanut oil & 0.13 & 0.55 & 0.87 & 2.12 & 6.58 & 11.46 & 10.25 & 4.44 & 3.36 & 3.93 & 8.99 & 13.09 & 18.35 & 15.89 & 100.00 \\
\hline $80 \% \mathrm{MF}+20 \%$ peanut oil & 0.07 & 0.77 & 1.08 & 2.34 & 5.92 & 10.89 & 9.75 & 4.30 & 3.32 & 3.84 & 8.57 & 12.47 & 18.57 & 18.09 & 100.00 \\
\hline $100 \% \mathrm{MF}+0 \%$ corn oil & 0.13 & 0.41 & 0.95 & 2.13 & 7.18 & 12.11 & 11.17 & 4.67 & 4.01 & 5.37 & 9.14 & 14.39 & 17.50 & 10.84 & 100.00 \\
\hline $95 \% \mathrm{MF}+5 \%$ corn oil & 0.03 & 0.34 & 0.55 & 2.02 & 7.21 & 12.12 & 10.96 & 4.47 & 3.74 & 5.09 & 8.70 & 13.65 & 17.85 & 13.30 & 100.00 \\
\hline $90 \% \mathrm{MF}+10 \%$ corn oil & 0.14 & 0.20 & 0.74 & 1.92 & 5.90 & 10.06 & 9.11 & 4.06 & 3.76 & 4.97 & 8.37 & 13.81 & 19.91 & 17.05 & 100.00 \\
\hline $85 \%$ MF $+15 \%$ corn oil & 0.09 & 0.62 & 1.14 & 1.91 & 6.16 & 10.39 & 9.30 & 3.82 & 3.24 & 4.58 & 7.83 & 12.96 & 19.44 & 18.52 & 100.00 \\
\hline $80 \% \mathrm{MF}+20 \%$ corn oil & 0.18 & 0.54 & 0.64 & 1.77 & 5.05 & 8.75 & 7.86 & 3.56 & 3.39 & 4.63 & 7.84 & 13.32 & 21.44 & 21.02 & 100.00 \\
\hline $100 \% \mathrm{MF}+0 \%$ olive oil & 0.26 & 0.67 & 1.30 & 3.60 & 7.96 & 11.64 & 10.08 & 5.47 & 5.43 & 6.58 & 9.96 & 13.90 & 15.03 & 8.12 & 100.00 \\
\hline $95 \%$ MF $+5 \%$ olive oil & 0.42 & 0.65 & 1.31 & 3.41 & 7.51 & 11.07 & 9.55 & 5.23 & 4.52 & 6.16 & 9.49 & 13.41 & 15.32 & 11.95 & 100.00 \\
\hline $90 \% \mathrm{MF}+10 \%$ olive oil & 0.23 & 0.66 & 1.12 & 2.95 & 6.47 & 9.63 & 8.19 & 4.53 & 4.69 & 5.92 & 9.13 & 13.08 & 16.36 & 17.06 & 100.00 \\
\hline $85 \%$ MF $+15 \%$ olive oil & 0.26 & 0.70 & 1.30 & 3.23 & 6.37 & 11.28 & 9.93 & 5.41 & 5.28 & 6.28 & 9.29 & 12.66 & 14.77 & 13.24 & 100.00 \\
\hline $80 \% \mathrm{MF}+20 \%$ olive oil & 0.19 & 0.62 & 1.01 & 2.27 & 6.39 & 9.67 & 8.13 & 4.45 & 4.47 & 5.48 & 8.21 & 11.77 & 15.83 & 21.51 & 100.00 \\
\hline $100 \%$ MF $+0 \%$ soy oil & 0.33 & 0.78 & 1.64 & 4.99 & 10.13 & 12.13 & 9.37 & 5.75 & 5.20 & 7.66 & 11.48 & 13.59 & 11.39 & 5.56 & 100.00 \\
\hline $95 \% \mathrm{MF}+5 \%$ soy oil & 0.36 & 0.93 & 1.49 & 4.85 & 9.87 & 11.89 & 9.05 & 5.56 & 5.96 & 7.11 & 10.02 & 11.80 & 11.32 & 9.80 & 100.00 \\
\hline $90 \% \mathrm{MF}+10 \%$ soy oil & 0.34 & 0.98 & 1.67 & 5.35 & 10.36 & 12.12 & 8.98 & 5.41 & 5.64 & 6.67 & 9.08 & 10.43 & 11.59 & 11.39 & 100.00 \\
\hline $85 \%$ MF $+15 \%$ soy oil & 0.35 & 0.99 & 1.81 & 5.71 & 11.11 & 13.04 & 9.87 & 5.97 & 6.31 & 7.47 & 10.22 & 11.25 & 9.75 & 6.16 & 100.00 \\
\hline $80 \%$ MF $+20 \%$ soy oil & 0.50 & 1.06 & 2.32 & 4.86 & 12.87 & 13.92 & 9.86 & 5.33 & 5.04 & 5.97 & 7.64 & 8.43 & 10.57 & 11.62 & 100.00 \\
\hline $100 \% \mathrm{MF}+0 \%$ pork lard & $\mathrm{ND}^{1}$ & 0.88 & 3.18 & 8.25 & 11.83 & 9.26 & 5.33 & 4.50 & 6.16 & 9.75 & 15.48 & 17.24 & 8.13 & ND & 100.00 \\
\hline $95 \% \mathrm{MF}+5 \%$ pork lard & $\mathrm{ND}$ & 0.67 & 2.67 & 8.13 & 12.28 & 9.97 & 5.72 & 4.69 & 6.11 & 9.23 & 14.66 & 18.41 & 7.46 & ND & 100.00 \\
\hline $90 \% \mathrm{MF}+10 \%$ pork lard & ND & ND & 2.45 & 7.77 & 12.36 & 10.21 & 5.89 & 4.79 & 6.12 & 8.98 & 14.52 & 19.77 & 7.13 & ND & 100.00 \\
\hline $85 \% \mathrm{MF}+15 \%$ pork lard & ND & 0.37 & 2.20 & 6.84 & 10.84 & 9.03 & 5.25 & 3.89 & 5.59 & 9.82 & 15.03 & 22.47 & 8.66 & ND & 100.00 \\
\hline $80 \% \mathrm{MF}+20 \%$ pork lard & ND & 0.59 & 2.55 & 6.98 & 10.20 & 8.15 & 4.68 & 3.84 & 5.11 & 7.99 & 14.83 & 25.44 & 9.64 & ND & 100.00 \\
\hline $100 \% \mathrm{MF}+0 \%$ bovine tallow & ND & 0.77 & 3.83 & 9.55 & 11.94 & 8.75 & 4.93 & 5.15 & 7.33 & 11.32 & 15.58 & 14.29 & 6.56 & ND & 100.00 \\
\hline $95 \% \mathrm{MF}+5 \%$ bovine tallow & $\mathrm{ND}$ & 0.71 & 3.11 & 8.52 & 11.13 & 8.40 & 5.67 & 5.28 & 7.45 & 11.78 & 16.43 & 15.17 & 6.35 & ND & 100.00 \\
\hline $90 \% \mathrm{MF}+10 \%$ bovine tallow & ND & ND & 2.39 & 7.10 & 9.79 & 7.30 & 4.55 & 4.42 & 7.07 & 12.74 & 18.85 & 17.99 & 7.81 & ND & 100.00 \\
\hline $85 \% \mathrm{MF}+15 \%$ bovine tallow & ND & ND & 1.77 & 5.91 & 8.54 & 6.60 & 4.18 & 4.48 & 7.56 & 13.44 & 19.85 & 19.16 & 8.50 & ND & 100.00 \\
\hline $80 \% \mathrm{MF}+20 \%$ bovine tallow & $\mathrm{ND}$ & ND & 1.58 & 5.76 & 8.42 & 6.26 & 3.94 & 4.26 & 7.42 & 13.68 & 20.34 & 19.67 & 8.66 & ND & 100.00 \\
\hline
\end{tabular}

${ }^{1} \mathrm{ND}=$ nondetectable $(<0.01, \% \mathrm{wt} / \mathrm{wt})$. 
Table 5. Correct classification percentages by linear discriminant analysis

\begin{tabular}{lcccccrr}
\hline & \multicolumn{9}{c}{ Oil } & & \\
\cline { 2 - 5 } Sample & Fish & Peanut & Corn & Olive & Soy & Pork lard & Bovine tallow \\
\hline Pure milk fat $(\mathrm{n}=216)$ & 87.2 & 94.6 & 98.7 & 98.1 & 100.0 & 98.2 & 86.8 \\
$5 \%$ adulteration & 76.6 & 90.4 & 95.7 & 96.7 & 100.0 & 98.2 & 73.7 \\
$10 \%$ adulteration & 78.0 & 93.1 & 96.4 & 98.1 & 100.0 & 98.2 & 75.0 \\
$15 \%$ adulteration & 79.6 & 95.1 & 96.4 & 98.1 & 100.0 & 98.2 & 77.0 \\
$20 \%$ adulteration & 91.4 & 97.1 & 97.6 & 98.1 & 100.0 & 99.3 & 89.5 \\
\hline
\end{tabular}

leic acid, had higher levels of C52 with values of 59.0, $66.21,66.25$, and $74.54 \%$, respectively; only peanut oil registered C54, due to its elevated content of linoleic, arachidic, arachidonic, and lignoceric acids. Pork lard was characterized by its C50 $(61.88 \%)$ content, whereas in bovine tallow, C48, C50, and C52 accounted for $85.42 \%$ of the total; these fats are sources of palmitic and stearic acids (Murray et al., 2005).

\section{Detection of NMF in MF}

The results of TAG composition in physical mixtures of MF and NMF (at 5, 10, 15, and 20\%) are shown in Table 4. When the adulterant was pork lard, the content of C36 to C46 was decreased and C50 increased proportionally to the adulteration level. This was expected, because pork lard has no C36 to C44 TAG and C46 has less presence compared with the levels found in pure MF (Table 1), even though the C50 content in pork lard is 3 times greater than that in pure MF. When bovine tallow was the adulterant, levels of TAG C32 to C40 decreased and levels of C46 to C52 increased proportionally to the adulteration index; this behavior was due to the absence of low-molecular-weight TAG and to the elevated content of high-molecular-weight TAG (C46 to C52) in bovine tallow.

A simple regression analysis was developed to show the relation of the adulteration percentage (level) versus TAG proportion (\% wt/wt) with variables MF mixtures with pork lard and bovine tallow. The results produced regression equations that correctly described the relation between the 2 variables, because the determination coefficients were between 0.92 and 0.96 .

When oils were the adulterants, the pattern of behavior in the increasing levels of addition was similar to that observed with pork lard and bovine tallow. In general, the content of C52 in all the analyzed oils was 2 to 3 times greater than that in MF, except in fish oil, in which C52 content was 1.5 times greater. Figures 1 and 2 show the relationship in each level of adulteration of MF with peanut and corn oils.

These results proved that the TAG content in MF changes as a function of the NMF addition level, which justifies the use of a mathematical model (Timms, 1980) for the group formation in TAG content of authentic MF and that mixed with NMF; this method yields time and analysis cost savings.

\section{LDA and Detection of MF Adulterations}

To reduce the universe of 11 variables (C34 to C54 triacylglycerols), an analysis of principal components was performed to leave only the variables that contribute the most information (SPSS, 1997; Afifi et al., 2004); that is, C36, C48, and C52. These variables were used in a first discriminant analysis for MF adulteration with bovine tallow, which allowed correct classifications in $43.4 \%$ of samples. This result motivated us to perform another LDA with step-by-step variable selection from C34 to C54 (SPSS, 1997; Afifi et al., 2004). This selection procedure offered an interval of 5 to 8 variables that depended on the fat used as adulterant.

The 5 groups of fats formed ( 1 of pure MF and 4 with adulterations at $5,10,15$, and $20 \%$ ) allowed us to mathematically find 4 discriminant functions. However, not all had the same power to separate the groups; the first function had the greatest power of classification, and consequently, all calculations were based on such a function.

The evaluated centroid groups in the discriminant function correspond to the mean of the discriminant scoring for each group over the function. The graphic study is of great importance to examine the separation of centroid groups and their relative position. In this way, histograms of absolute frequency of the discriminant scores are obtainable, and group separation is clear by visual inspection (Figure 3).

The classification of the 216 cases in the 5 proposed groups is shown in Table 5 . In global terms, the correct classification percentages vary in a range from 80 to $100 \%$, except when the adulterant was fish oil. The groups formed with fish oil as adulterant had correct classification percentages of $79.4,78.0,79.6$, and 91.4 with addition levels of $5,10,15$, and $20 \%$, respectively. The correct classification of the 216 originally grouped cases was $82.50 \%$. When peanut oil was used as adul- 
terant, correct classification between 85 to $98.1 \%$ was obtained. The overall correct classification for all fat groups was $94.1 \%$. When soy oil was used as adulterant, the discriminant analysis was satisfactory at $100 \%$ of the cases. Corn and olive oils reflected an elevated index of correct classification only when the adulteration level was 5\%; in both cases, percentages were 95.7 and $93.4 \%$, respectively. When adulteration levels increased, classification percentages went up to $100 \%$.

One reason why this model of foreign fat detection in milk and dairy products is proposed is the identification of NMF of animal origin, because NMF of vegetable origin can be detected relatively easy by using the phytosterols test (NMX-F707-COFOCALEC-2004). Adulterations with pork lard and bovine tallow could be detected above $97 \%$ in the majority of groups; however, a strange behavior was observed with bovine tallow, and consequently, the obtained results were not considered conclusive.

The results reached with LDA represent an important advance in the study of MF adulterations in Mexico. Nevertheless, it is convenient to pursue these studies to reduce the variability of data; perhaps the level of detection reached by Precht (1992a, b) will be obtained. Precht (1992a, b) identified, by multiple regression equations, additions of vegetable origin fats (soy, palm, sunflower, olive, and coconut oils) and animal (pork lard and bovine tallow) to MF in levels up to $2 \%$.

In another study done in Chilean milk (Pinto et al., 2002), LDA was applied based on TAG of 72 MF samples, obtaining 3 functions that identified adulterations of $5 \%$ in $88.3 \%$ of the cases. Nevertheless, the percentage reached is below that found in this study (92.4\%), which indicates the probability to keep on increasing, a posteriori, the correct classification levels.

\section{Quality Control of UHT MF}

Triacyglycerol values found in the 36 samples of UHT MF marketed in Mexico City were subjected to an evaluation under the obtained LDA functions with the objective to evaluate the fat authenticity. It was found that $16.7 \%$ of fats from industries 1 and $3 \mathrm{did}$ not fall in the authentic MF category, and $83.3 \%$ of the samples from industry 2 did not fall in the authentic MF category. We conclude that LDA is reliable in the detection of adulterations at levels of $5 \%$ or less in industrialized MF.

\section{CONCLUSIONS}

The discriminant analysis applied to selected variables by main components did not yield encouraging results in the detection of MF adulterations. Never- theless, the selected step-by-step method based on the distance of Mahalanobis improved the variable group and, consequently, the correct classification percentage. The global percentage of satisfactory classification was $94.4 \%$; consequently, the method was effective in detecting adulterations at levels $<10 \%$. The analysis results from GC of TAG contained in UHT MF were subjected to the LDA functions, demonstrating that at least one industry added NMF to its UHT milk in $80 \%$ of the analyzed samples. The results obtained in this research assist in a possible proposal of a national norm that verifies MF authenticity in milk and dairy products.

\section{ACKNOWLEDGMENTS}

The authors acknowledge and appreciate the National Council on Science and Technology (Mexico City, Mexico) for financing for the development of this work under project No. 52610 .

\section{REFERENCES}

Afifi, A., A. V. Clark, and S. May. 2004. Computer aided multivariate analysis. 4th ed. Chapman \& Hall/CRC, Boca Raton, FL.

Destaillats, F., M. de Wispelaere, F. Joffre, P. A. Golay, B. Hug, F. Giuffrida, L. Fauconnot, and F. Dionisi. 2006. Authenticity of milk fat by fast analysis of triacylglycerols: Application to the detection of partially hydrogenated vegetable oils. J. Chromatogr. A 1131:227-234.

European Community. 2001. Métodos que deben utilizarse para el análisis y evaluación de la calidad de la leche y de los productos lácteos. Reglamento (CE) No. 213/2001. Off. J. L 037:07/02/01.

Fontecha, J., G. T. Mayo, and M. Juárez. 2006. Triacylglycerol composition of protected designation of origin cheeses during ripening. Authenticity of milk fat. J. Dairy Sci. 89:882-887.

Frank, C., E. H. Smith, H. E. Brauwn, A. Holdrinet, and J. W. Mc Wade. 1975. Organochlorine insecticides and industrial pollutants in the milk supply of the Southerm Region of Ontario, Canada. J. Milk Food Technol. 38:65-72.

Gutiérrez, R., S. Vega, G. Díaz, H. J. Delgadillo, G. Urbán, A. Ramírez, C. González, and I. Méndez. 2007. Detección de grasa extraña en grasa láctea por cromatografía de gases y estadística multivariable. Agrociencia 41:733-742.

IDF/FIL (International Dairy Federation/Federación Internacional de Lechería). 1995. Milk and milk products. Guidance sampling. FILIDF Standard 50C. IDF/FIL, Brussels, Belgium.

Juárez, M. 1983. Aplicaciones de las técnicas cromatográficas al control de calidad de los productos lácteos. Rev. Agroquim. Tecnol. Aliment. 23:467-485.

Molketin, J. 2007. Detection of foreign fat in milk fat from different continents by triacylglycerol analysis. Eur. J. Lipid Sci. Technol. 109:505-510.

Murray, R. K., P. A. Mayes, D. K. Granner, and V. W. Rodwell. 2005. Harper Illustrated Biochemistry. Manual Moderno, Mexico City, Mexico.

Parodi, P. W. 1971. Detection of synthetic and adulterated butterfats. III Triglyceride and fatty acid analysis. Aust. J. Dairy Technol. 26:155-158.

Parodi, P. W. 1973. Detection of synthetic and adulterated butterfats. IV. GLC triglyceride analysis. Aust. J. Dairy Technol. 28:39-41.

Pérez, F. N. A., G. G. Díaz, T. R. Gutiérrez, L. S. Vega, C. G. Urbán, F. M. G. Prado, L. M. M. González, A. A. Ramírez, and C. M. Pinto. 1998. Composición en ácidos grasos de la grasa de leches pasteurizadas mexicanas. Vet. Méx. 29:329-335. 
Pinto, C. M., M. O. Contreras, R. E. Carrasco, C. C. Brito, H. C. L. Molina, S. K. Ah-hen, and S. L. Vega. 2002. Determinación de la autenticidad de grasas lácteas. Análisis discriminante lineal de triacilglicéridos. Agro Sur. 30:59-67.

Pinto, C. M., P. Fernández de la Reguera, and S. B. Villanueva. 1987. Detección y cuantificación de adulteraciones en grasa láctea. Análisis de regresión múltiple. Agro Sur. 15:32-38.

Precht, D. 1992a. Detection of foreign fat in milk fat. Lebensm. Unters. Forsch. 94:1-8.

Precht, D. 1992b. Detection of foreign fat in milk fat. Lebensm. Unters. Forsch. 194:107-114.
SPSS. 1997. Guía del usuario del sistema base de SPSS 7.5 para Windows. SPSS Inc., Chicago, IL.

Timms, R. E. 1980. Detection and quantification of non-milk fat in mixtures of milk and non-milk fats. J. Dairy Res. 47:295-303.

Vega, S., N. Pérez, M. Pinto, G. Díaz-González, R. Gutiérrez, G. Urbán, M. M. González, G. Prado, and A. Ramírez. 1999. Composición en ácidos grasos y triglicéridos de leche pasteurizada comercializada en la Ciudad de México. Rev. Salud Anim. 21:1-4. 